\title{
Redefining Ecological Engineering in the Context of Circular Economy and Sustainable Development
}

\author{
Andreas Schönborn ${ }^{1}$ (D) $\cdot$ Ranka Junge ${ }^{1}$ \\ Received: 19 February 2021 / Accepted: 3 March 2021 / Published online: 2 April 2021 \\ (C) The Author(s) 2021
}

\begin{abstract}
In the past decades, the search for a more sustainable way of global development has increased in importance in international politics and economy. A driving force is the continuing degradation of the environment in many areas of the world, often caused or accelerated by population growth and climate change. Sustainable development is seen as key approach to mitigate these processes. It has been defined as "development that meets the needs of the present without compromising the ability of future generations to meet their own needs." But how can this ambitious goal be achieved in the light of numerous global challenges? Engineering is a very influential human practice and must be addressed in this context. Engineers are crucially involved in design and construction of our built environment and thus in shaping almost its entire development. However, when designing a solution for a given problem, effects caused outside of the system borders are often not considered. If this is combined with a narrowly confined linear problem-solving approach, it is inherently prone to create new environmental challenges. We postulate that the development of a new design paradigm for engineering must be part of the progress towards sustainable development. We think that this new paradigm needs to integrate a sound understanding of ecological principles, processes, and interdependencies as well as thorough system thinking. We call this ecology-inspired approach to engineering "ecological engineering" and redefine it as follows: Ecological Engineering integrates ecological principles, processes, and organisms with existing engineering practice to a holistic approach for problem-solving. In this paper, we explore the historical development of earlier definitions of Ecological Engineering in the light of their underlying value systems. Based on this analysis, we propose a new conceptual approach for Ecological Engineering and define seven principles that point the way towards a future label that can be conferred to Good Ecological Engineering Practice.
\end{abstract}

Andreas Schönborn

andreas.schoenborn@zhaw.ch

1 Institute of Natural Resources Science, Zurich University of Applied Science, Grüental 14,

CH-8820 Wädenswil, Switzerland 
Keywords Ecological Engineering · Redefinition · Engineering design · Circular Economy · Principles

\section{Introduction: A Quest for a New Kind of Engineering}

In the past decades, the search for a more sustainable way of global development has increased in importance in international politics and economy. A milestone was the 2030 Agenda for Sustainable Development, which defines 17 Sustainable Development Goals (SDGs), encompassing 169 targets and the aim to "transform our world" [1]. This agenda was followed by the Paris Climate Accord in December 2015, which defined concrete steps to reduce greenhouse gas emissions and promote a climate-resilient development [2].

The driving force behind these international agreements is the continuing degradation of the environments, often caused or accompanied by climate changes. Water scarcity caused by unprecedented drought, e.g., in the Middle East [3], rainforest destruction in the Amazon [4] or on Borneo [5], declining fish catch [6], or the increasing amount of plastics in the Ocean [7], shows that the current strategy against this massive degradation is still not effective. As a consequence, the planetary boundaries [8], the "capacity of the planet to provide many of the resources we use and to accommodate our emissions," are being exceeded, "while many of the planet's inhabitants cannot meet even their most basic needs" [9].

Sustainable development has been defined as "development that meets the needs of the present without compromising the ability of future generations to meet their own needs" [10]. But how can this ambitious goal be achieved, when facing challenges like those mentioned above in the light of a growing human population on Earth?

Engineering is a very influential human practice and must be addressed in this context. Engineers are crucially involved in design and construction of our built environment and thus in shaping of almost the entire development of our civilization. In the context of engineering for sustainable development, Dodds and Venables [9] state that "often it will be - and should be - engineers who lead processes of making decisions about the use of material, energy and water resources, the development of infrastructure, the design of new products and so on."

However, engineering, as do any other human activities, also contributes its share to the global problems. Engineering solutions are commonly based on a given problem statement by a customer and focused on the design of a solution for this customer. The system borders are often narrowly confined by the problem owner, and the design process is linear. Linear design

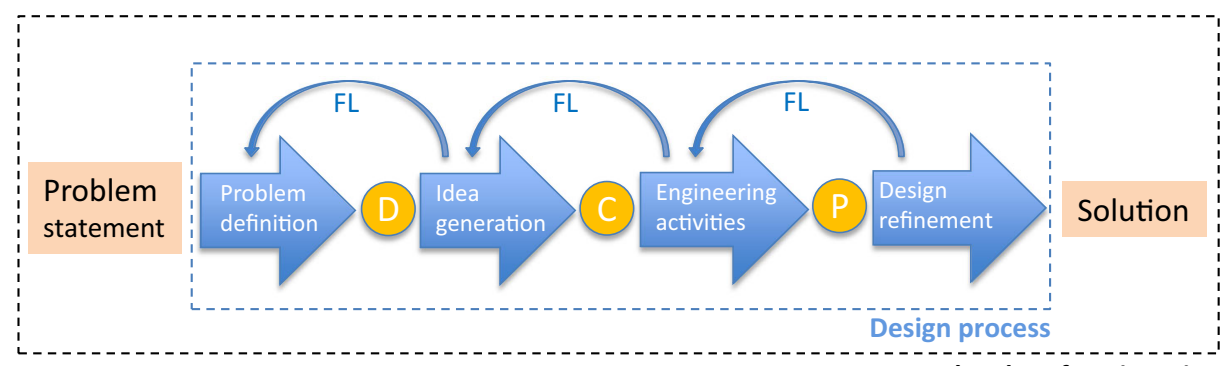

System border of engineering

Fig. 1 Conceptual model of a typical linear problem-solving process in engineering design. D, operationalized problem definition; C, concept; P, prototype; FL, feedback loop. Adapted after Sobek and Jain [12] 
processes have been extensively described in design research literature (e.g., [11]), and the steps of a linear problem-solving approach in engineering design are visualized in Fig. 1.

The example of the historical development of wastewater treatment in the industrialized countries since the mid-1800s [13] illustrates how an initial problem statement and its solution can lead to a system of subsequent follow-up problem statements. In combination with the linear problem-solving process, this undermines efforts to achieve the goals of sustainable development.

Sewer-based sanitation as we know it in Europe today started in the nineteenth century [14]. Public health became a major problem in the then rapidly growing cities. The proximity of drinking water wells and faecal matter disposal was understood to be the culprit. Accelerated by the increasing popularity of flush toilets and after controversial discussions that stretched over several decades, the alluvial sewer system prevailed over the approach of collecting fecal matter and conveying it out of town for reuse in agriculture [14].

A consequence of discharging human wastes into sewers without treatment was a dramatic increase of pollution of the receiving waters [14]. The first primary treatment devices (settling and removal of solids) were built around 1860 and improved from then on. They were stepwise followed by biological treatment (BOD-removal, around 1900) and nutrient removal (nitrification, phosphorus precipitation, denitrification, since the 1960s). In the 1990s, micropollutants and endocrine disruptors moved to the focus, and some highly industrialized countries are now removing them, e.g., by using active carbon filtration [15]. Since about 2010 , microplastics are increasingly gaining attention. With every new water quality requirement to this end-of-pipe system, a new problem statement was formulated, leading over time to the cascade of treatment steps we find in today's wastewater treatment plants.

The series of consecutive problem statements and engineering activities described above was driven by the need to restore the quality of the receiving waters. Undoubtedly, this system removes pollutants from wastewater very effectively and has contributed a lot to water quality. In the future however, nutrients should be recovered for food production, and water should be preserved. In this context, the "classical" approach to handling human waste (Fig. 2) has several shortcomings: (A) Ammonia and nitrate are mostly transformed into molecular nitrogen and released to the atmosphere; (B) Phosphorus is precipitated and accumulates in the sludge, which is increasingly incinerated with the ash being landfilled [16]; (C) Soluble nutrients, such as potassium, are discharged with the treated wastewater. Furthermore, (D) the sewer system requires a constant flow of water to avoid the accumulation of solids. At the same time, (E) heavy rain leads to combined sewer overflow which leads to a discharge of untreated wastewater to the receiving water. Finally, $(F)$ the entire system offers no incentive for individual consumers to use less water. Both (D) and (F) also accentuate water scarcity in drought situations. All this suggests that the current approach may not be adequate for achieving the sustainable development goals.

In our view, future problem-solving processes in engineering design need to be circular (Fig. 3). The classic linear problem-solving process in engineering design becomes an element embedded in the context of the circular problem-solving process. In this mental model, problem statements and their solutions are connected: each output produced by a solution ( $\mathrm{S}$ in Fig. 3) becomes the problem statement (P in Fig. 3) of the following process, until the cycle is closed. Resources are reused within the cycle as much as possible or are handed over to another cycle, and discharge or waste disposal to nature is minimized. The in- and outputs are kept as close to zero as possible. Consequently, avoiding harmful substances that may 


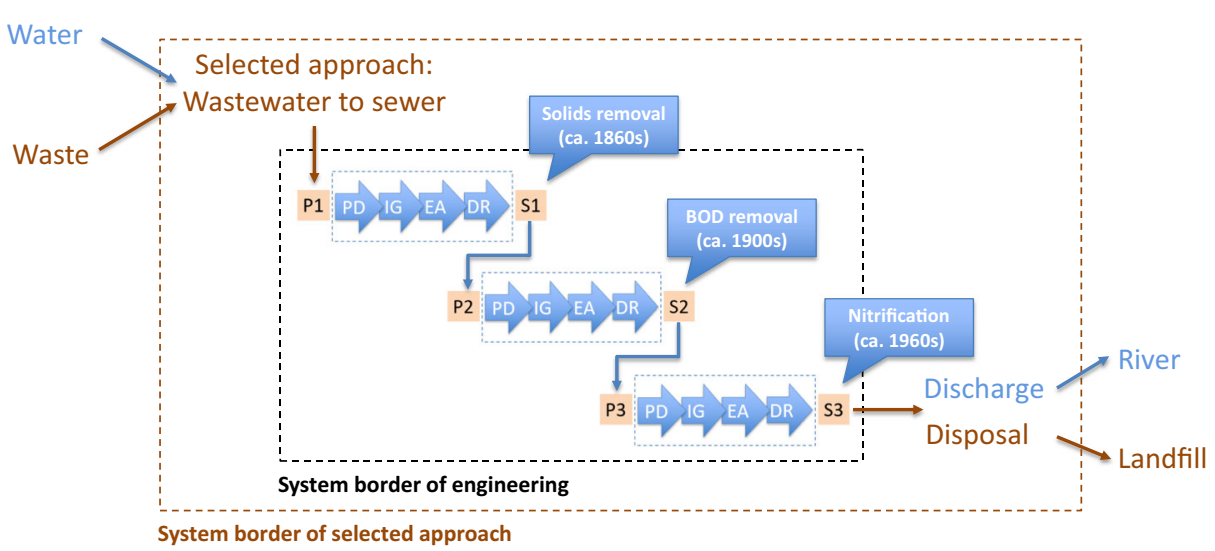

Fig. 2 "Classical" problem-solving at the example of the historical development of engineering solutions for wastewater treatment in Europe (simplified). P, problem statement; S, solution; PD, problem definition; IG, idea generation; EA, engineering activities; DR, design refinement

accumulate in the cycle is also part of the engineering design. The concept of industrial symbiosis de-facto already follows this principle [17, 18].

But how can this be achieved? Ecologists have been systematically examining and describing nature's cycles for more than 150 years now. The building blocks of the global nitrogen cycle [19] as well as the global carbon cycle [20] were discovered in the nineteenth century. Is it possible to derive a broad set of principles from this large body of knowledge that informs a new type of engineering that is inspired by ecology and that may point the way to a sustainable development?

The idea of integrating ecology and engineering into a new discipline has in fact been compelling and attractive for many professionals in the past decades. According to Mitsch [21]

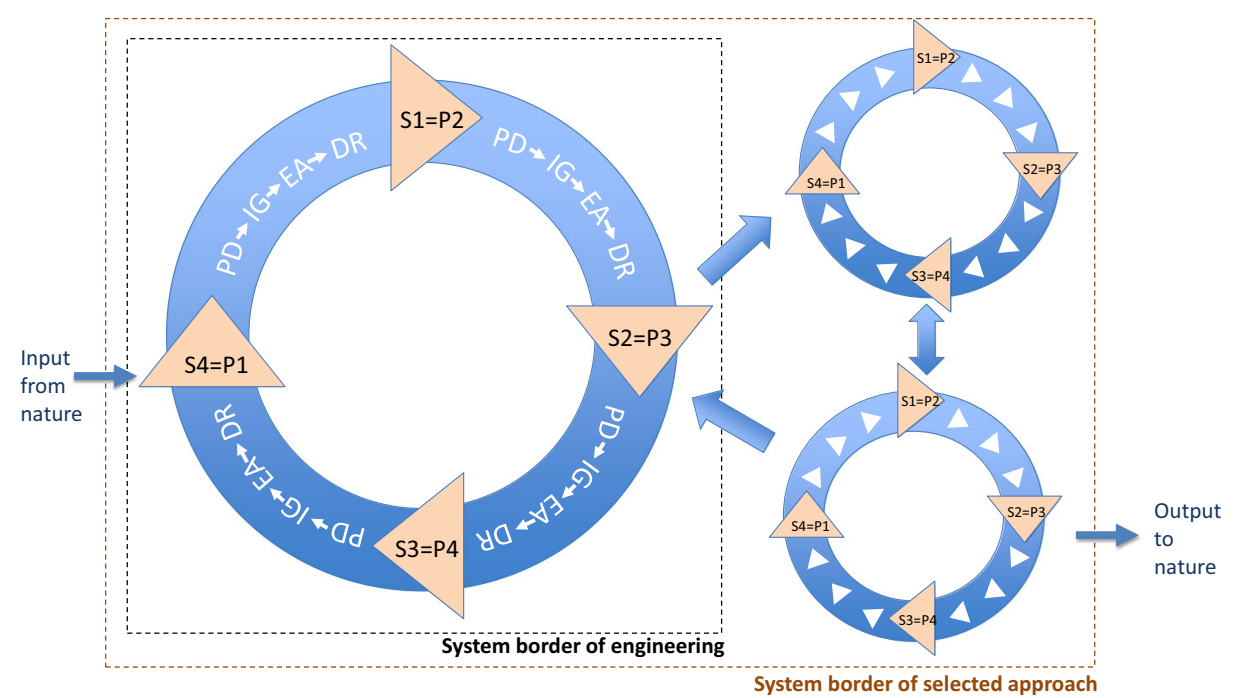

Fig. 3 Conceptual model of a circular problem-solving process in engineering design. P, problem statement; S, solution; PD, problem definition; IG, idea generation; EA, engineering activities; DR, design refinement 
"Ecological engineering was defined by H.T. Odum in the early 1960s" as "management of nature," with "singular aspects supplementary to those of traditional engineering," concluding that "partnership with nature is the better term." A number of text books (Busch et al. [22], Mitsch \& Jørgensen [23], Kangas [24], van Bohemen [25]) and conference proceedings ([26-31]) have been published, and since Odium's time, "several in the field have offered definitions in hopes of capturing the essence" of the field [32]. Consequently, different definitions of ecological engineering exist today.

In this paper, we examine the existing definitions of Ecological Engineering and propose a redefinition, which should provide an umbrella for a broad range of engineering activities in the context of sustainable development: Ecological Engineering integrates ecological principles, processes and organisms with existing engineering practice to a holistic approach for problem-solving.

In following chapters, crucial terms are defined, and the methodology is explained (the "Terminology and Methods" section). A selection of frequently used previous definitions of ecological engineering will be reflected (the "Ecological Engineering Definitions" section). We aim to show that the existing definitions are too restrictive in the context of sustainable development and argue why in our view a redefinition is necessary. The proposed redefinition of ecological engineering is explored in the "Redefining Ecological Engineering" section. A concept and potential tools for a circular, holistic problem-solving process are proposed. A set of seven principles are formulated to measure the outcome of this new process. Finally, the "Conclusion" section summarizes the findings and provides an outlook on the future of ecological engineering in the context of sustainable development.

\section{Terminology and Methods}

\section{Terminology}

The terms environment and nature are often used as synonyms (all italic terms in this chapter are defined in Table 1). Historically, however, nature originates from the Latin word natura and has been used for at least two millennia, while environment was coined by Thomas Carlyle in 1828 [39].

The term environment stands for an anthropocentric understanding of life on Earth. It excludes humans and things created by humans and regards living beings and inanimate things as distinctly different from humans (Fig. 4). This understanding lends hand to freely utilizing the environment, which can be transformed, manipulated, and exploited.

In contrast, the term nature usually encompasses all living beings including humans and the inanimate things not created by humans. In the context of a holistic understanding of engineering, we extend the perspective and consider human creations also as a part of nature. The terms anthropocentric and holistic are used as antonyms in this study.

Considering that the way of engineering is heavily influenced by the way of thinking, we furthermore distinguish two general types of design thinking in this study. Linear thinking follows the linear problem-solving process (Figs. 1 and 2) and mostly disregards the broader context, such as waste outputs and feedback loops beyond the system border. Circular thinking looks for cycles on different scales of a system, prefers circular over linear material flows, looks for feedback loops, and regards waste as part of the design process and a resource in the cycle (Fig. 3). Linear and circular thinking are used as antonyms in this study. 
Table 1 Crucial terms in this study and their understanding

Holistic

Anthropocentric

Circular thinking

Linear thinking

Nature

Environment

Ecology

Engineering
Definition: "Dealing with or treating the whole of something or someone and not just a part" [33]. In this study, it stands for the aim to look at the larger context of a problem and balance human wishes and the needs of the ecosphere, "for the benefit of both" [21]. Used as antonym to anthropocentric.

Definition: "interpreting or regarding the world in terms of human values and experiences" [34]. In this study, anthropocentric stands for a unilateral attitude that focuses on the utility for humans. Used as antonym to holistic.

Definition: We define "circular thinking" as a way of design thinking that looks for cycles on different scales of a system. It prefers circular over linear material flows, looks for feedback loops, and regards waste as a resource in the cycle. In this study, circular thinking is used as antonym to linear thinking. This thinking is de facto very similar (or even the same) to the concept of "complex adaptive systems thinking" as defined Biggs et al. [35].

Definition: We define "linear thinking" as linear (sequential) way of thinking for problem-solving (see the "Introduction: A Quest for a New Kind of Engineering" section). In this study, it is used as antonym to circular thinking.

Definition: "the external world in its entirety" [36], based on the Latin word natura, describes the inmost feature of a living being or an object.

In this study, the term "nature" stands for the holistic view that humans and our creations are part of nature. This is de facto very similar to the concept of Biggs et al. [35], where humans are regarded as a part of the biosphere, this resulting in interwoven socio-ecological systems (SES).

Definition: "The circumstances, objects, or conditions by which one is surrounded" [37]. In this study, the term "environment" stands for the anthropocentric view that humans are different from nature.

Definition: The scientific field that analyzes and studies the interactions among organisms and their environment [37]. Descriptive ecology is an accurate accounting of the diversity of life on Earth, while functional ecology focusses on processes and functions.

Definition: The application of science and mathematics by which the properties of matter and the sources of energy in nature are made useful to people [38].

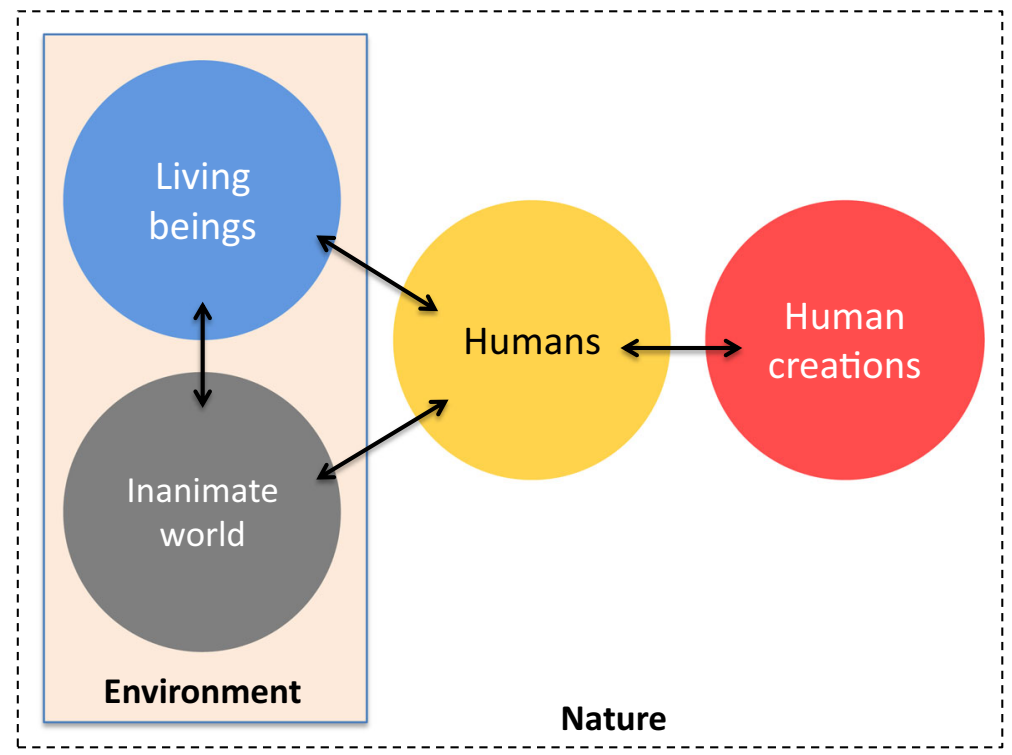

Fig. 4 Conceptual distinction between the terms "environment" and "nature," as used in this study 


\section{Methodology}

A literature search was conducted with the key words "ecological engineering" OR "ecotechnology" OR "ecotechnics" (in the title), AND the key word "definition" (in the full text). The search was conducted in "Web of Science" [40] and in Google Scholar [41] in January 2021. The key words "eco-design" and "ecological design" were not included.

The selection of the definitions (the "Type of Interaction with nature" section) was based on the following criteria:

1. Contains a formal definition of ecological engineering (or the related terms)

2. Focusses on integrating ecology and engineering

3. Definition on an abstract level (e.g., human society, future societies, nature, ecosystems...), thus applicable to variable geographical locations and application fields

4. More than 10 citations are listed in Google Scholar [41]

5. Published in or after 1989 (= publication date of [23])

The selected definitions are listed and assessed in the "Ecological Engineering Definitions" section.

\section{Ecological Engineering Definitions}

The literature survey on "Ecological Engineering" AND "definition" yielded 6 publications with definitions of ecological engineering that comply with the selection criteria (the

Table 2 List of definitions of Ecological Engineering, in chronological order of publication

\begin{tabular}{|c|c|c|c|}
\hline & Author & Definition/description & Cited* \\
\hline 1989 & Busch et al. [22] & $\begin{array}{l}\text { By ecotechnology (German: Ingenieurökologie), we understand the } \\
\text { engineering implementation of ecological knowledge and principles } \\
\text { [translated with deepl.com] }\end{array}$ & 2 \\
\hline 1989 & $\begin{array}{l}\text { Mitsch and } \\
\text { Jørgensen [23] }\end{array}$ & $\begin{array}{l}\text { The design of human society with its natural environment, for the benefit } \\
\text { of both }\end{array}$ & 478 \\
\hline 1993 & Straškraba [42] & $\begin{array}{l}\text { Ecotechnology is defined as the use of technological means for ecosystem } \\
\text { management based on deep understanding of principles on which } \\
\text { natural ecological systems are built and on the transfer of such } \\
\text { principles into ecosystem management in a way to minimize the costs } \\
\text { of the measures and their harm to the global environment. }\end{array}$ & 67 \\
\hline 2001 & Bergen et al. [43] & $\begin{array}{l}\text { The design of sustainable systems, consistent with ecological principles, } \\
\text { which integrate human society with its natural environment for the } \\
\text { benefit of both }\end{array}$ & 325 \\
\hline 2003 & $\begin{array}{l}\text { H.T. Odum and B. } \\
\text { Odum [44] }\end{array}$ & $\begin{array}{l}\text { Ecological engineering is the study and practice of fitting environmental } \\
\text { technology with ecosystem self-design for maximum performance }\end{array}$ & 70 \\
\hline 2003 & $\begin{array}{l}\text { Mitsch and } \\
\text { Jørgensen [45] }\end{array}$ & $\begin{array}{l}\text { The design of sustainable ecosystems that integrate human society with its } \\
\text { natural environment for the benefit of both }\end{array}$ & 332 \\
\hline 2008 & Gosselin [46] & $\begin{array}{l}\text { Practical Ecological Engineering is... "the conception, implementation } \\
\text { and monitoring of the ecological component of a planning and/or } \\
\text { management project, for the benefit of human society, including its } \\
\text { environmental expectations"; Scientific ecological engineering is "the } \\
\text { scientifically development of tools, methods and concepts for direct use } \\
\text { in practical ecological engineering" }\end{array}$ & 44 \\
\hline
\end{tabular}

*Citations according to Google Scholar [41] 


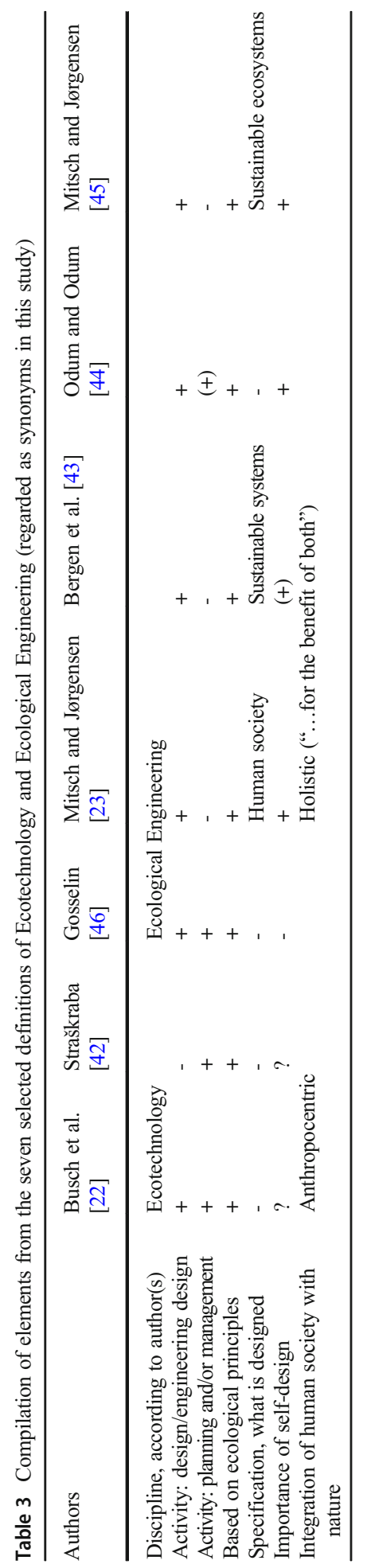


"Methodology" section). An additional publication, the German language textbook "Ingenieurökologie" by Busch et al. [22] was included in this selection. The seven definitions are summarized in Table 2; their elements are compared in Table 3.

The seven definitions will be discussed based on their type of interaction with nature (the "Type of Interaction with Nature" section) and the assumed underlying value system (the "Underlying Value System" section), as far as their publications allow for this distinction.

\section{Type of Interaction with Nature}

The process of engineering always implies that there is a problem that needs to be solved. Apart from this common denominator of the seven definitions in Table 2, there are overlaps and differences between them, depending on the focus either on management-related issues or on design (Table 3).

Three of the selected ecological engineering definitions focus on its application for either production, manipulation, and/or management: Busch et al. [22], Straškraba [42], and Gosselin [46]. Gosselin [46] uses the term planning, which implies a design component. Even though any engineering activity goes through a design step, their focus on management is distinctly different from the focus on the design process. Four definitions focus explicitly on design or engineering design (Mitsch \& Jorgensen 1989, Bergen et al. 2001, Mitsch \& Jorgensen 2003).

Regarding the type of interaction (Table 3, column 4), the definition by Mitsch and Jørgensen (1989), two major proponents of ecological engineering, focuses on the "design of human society with its natural environment" [21]. In 1993, they adapted this definition to "the design of sustainable ecosystems," because "we now believe, with hindsight, that 'the design of human society' was perhaps too ambitious a goal for a fledgling field and would be much more than engineers and scientists can or should do. In fact, it would be social engineering" [45]. The journal "Ecological Engineering" slightly reduced this definition to the "design of ecosystems for the mutual benefit of humans and nature"[47]. This well-established journal (5-year impact factor of 3.844) "plays a preponderant role" in the development of the field [48].

The focus on the design of ecosystems, e.g., for ecosystem restoration (which are often largescale objects or areas), seems to be currently dominating over other views of ecological engineering. This focus may be called the abundant space perspective of ecological engineering, exemplified by one of the largest ever designed ecosystems, the Everglades Nutrient Removal (ENR) project in Florida, part of which are six large-scale constructed wetlands covering 16,800 ha of land [49].

In Europe, the focus has been different. Many parts of Europe are densely populated. Land is often rare, can be very expensive, and competition for it is high. The remaining open stretches of land are often used for agriculture or are under protection (e.g., Nature 2000 areas). Limiting the Ecological Engineering to designing, building, or restoring ecosystems would thus be very restrictive for the development of the field in Europe.

International Ecological Engineering Society (IEES, founded 1992 in Utrecht, The Netherlands) therefore continued to use Mitsch's and Jørgensen's earlier definition of 1989 as working definition throughout the 1990s and 2000s. This broad definition allows to include, e.g., productive polycultures (which are managed production systems), constructions that support the linkage between natural ecosystems (i.e. wildlife bridges), or urban structures and buildings based on ecological principles (i.e., green roofs, green walls, and eco-villages). This focus may be called the limited-space perspective of ecological engineering. 
This view is shared by Bergen et al. [43], who argued that "applications for ecological engineering may stretch beyond working with ecosystems and influence all engineering practice, representing a new paradigm for engineering design." They proposed the definition of ecological engineering as "the design of sustainable systems, consistent with ecological principles."

Mitsch et al. published an extensive literature review on ecological engineering in China and compared the Western and Chinese approaches [50]. The authors concluded that production of food and valuable products (based on understanding of ecological principles) was one main goal of Chinese ecological engineering, while in the USA and the West, "the goal of ecological engineering projects is usually environmental protection."

Nevertheless, integrated fish production systems (also called Chinese polyculture), as they have been operated in China for many centuries, inspired ecological engineering pioneers in Western countries (e.g., [30, 51, 52]).

Recent reviews from the past 8 years (Zheng et al. [53], Liu et al.[54], Wu et al. ) as well as the upcoming "3rd International Conference on Advances in Civil and Ecological Engineering Research ACEER 2021" [55] demonstrate that ecological engineering is applied in China in different fields (e.g., pond aquaculture [54], forest restoration [53], and rural non-point source water pollution control [56]). However, no Ecological Engineering definition was found in these reviews. In the context of this study, we did not elucidate this issue further.

\section{Underlying Value System}

The ecological engineering definitions (Table 3) can as well be roughly classified as either anthropocentric or holistic. The traditional approach of engineering focuses on the usefulness of a project to humans. Natural systems may not be valued at all, like in open-pit mining, where the aim to extract minerals often overrides ecological considerations. If natural systems are valued, this value is based on functions (or services) for humans that can be expressed as a measurable value, such as food production, water retention, wastewater treatment, cooling, recreation, useful biodiversity (hunting game, food for hunting game...), etc. The first group of 3 definitions of Busch et al. [22], Straškraba [42], and Gosselin [46] follow this attitude, which we refer to as anthropocentric. This type of functions is also known as "ecosystem services" (Costanza et al 1998 [57]).

The second group of 4 definitions expresses the idea of a "partnership with nature" (Odum, cited in [21]) that aims for an integration "for the benefit of both" nature and humans ([21, 43-45]). Natural systems in this view have an intrinsic value, which goes beyond functions and services. We refer to these definitions as holistic.

The practical implementation of such a partnership of humans with nature is not an easy task. The term nature itself is an abstract category created by humans. It can be questioned if such a relationship can be called a partnership at all, since it is not based on equal terms. In case of disagreement between, e.g., city developers and advocates for nature, it will be up to a human court of justice, to interpret what exactly is the "benefit of both."

This option of choice is explicitly addressed by Gosselin [46] who asks: "Do we want to emphasize the alliance or partnership between humanity and nature, their inseparable nature (like the Odum school of ecological engineering), or do we have a more asymmetric view in which humanity has an increasing interest in nature conservation?" He chooses the asymmetric side and states that "in terms of defining the objectives of ecological engineering, I would prefer to maintain a humanist or anthropocentric approach, encompassing the widest possible range of management processes, including artificial ecosystem management." 
However, humans can learn to read and interpret nature. Processes, equilibria, and feedback mechanisms can be observed and evaluated by ecologists. In addition, if something is not beneficial for nature, it may also not be beneficial for humans. Finally, concerning a partnership with something or someone that cannot speak, as a species, we are capable to understand and care for severely disabled humans or animals even with very limited or no direct communication. This demonstrates that humans can choose the way they consider the needs of subjects with which (or whom) a direct communication is not possible. In conclusion, the development of a "mutually enhancing human-Earth relationship," as Garver [58] terms it, will ultimately require the transition towards new "novel law and governance systems" [58].

\section{Redefining Ecological Engineering}

In this chapter, we aim to examine the new definition Ecological Engineering integrates ecological principles, processes, and organisms with existing engineering practice to a holistic approach for problem-solving.

This redefinition contains three elements that will be discussed: How can ecological principles, processes and organisms be integrated into engineering practices? (the "Ecological Principles, Processes, and Organisms" section); what does holistic problem-solving encompass? (the "Holistic Problem Solving" section). Finally, several principles of Ecological Engineering are formulated, based on ecological principles (the "Principles of Ecological Engineering" section), which allow an assessment of how well an ecological engineering solution complies with them.

\section{Ecological Principles, Processes, and Organisms}

Insights from ecological research form the basis of the ecological engineering approach we are proposing here. However, how can ecosystems and ecological processes be a model for an engineering design approach?

Ecosystems show a large diversity dependent on geology, latitude, regional and local climate, water availability, soil structure, biogeographical history, local habitat, succession, neighboring habitats, and human influence (see ecology text books, e.g., [59]). Mature ecosystems are known to recycle nutrients to a high degree [60], while disturbed ecosystems [61] let a large share of nutrients pass through. Some ecosystems, such as e.g., Phragmites reeds, are almost monocultures, while others harbor a huge diversity of species. Changes of ecosystems are sometimes gradual and slow (e.g., the succession of plants on dunes ([59], p. 331) and sometimes sudden (e.g., when oxygen depletion in a lake causes fish kill). Changes can be reversible, if they do not exceed a certain limit or irreversible if a tipping point has been reached where the ecosystem switches to a new state. Last but not least, probably, all current ecosystems developed under increasing human influence that started more than 50,000 years ago [62].

A simple and comprehensive set of "essential governing principles of the biosphere" was proposed by Blum [63]: (i) solar orientation, (ii) closing material cycles, (iii) use of energy and materials in cascades, (iv) concentration of surplus (but no dissipation), (v) maximum variety, and (vi) networking of decentralized systems. The principles proposed in the "Principles of Ecological Engineering" section were developed based on these 6 principles of Blum. 


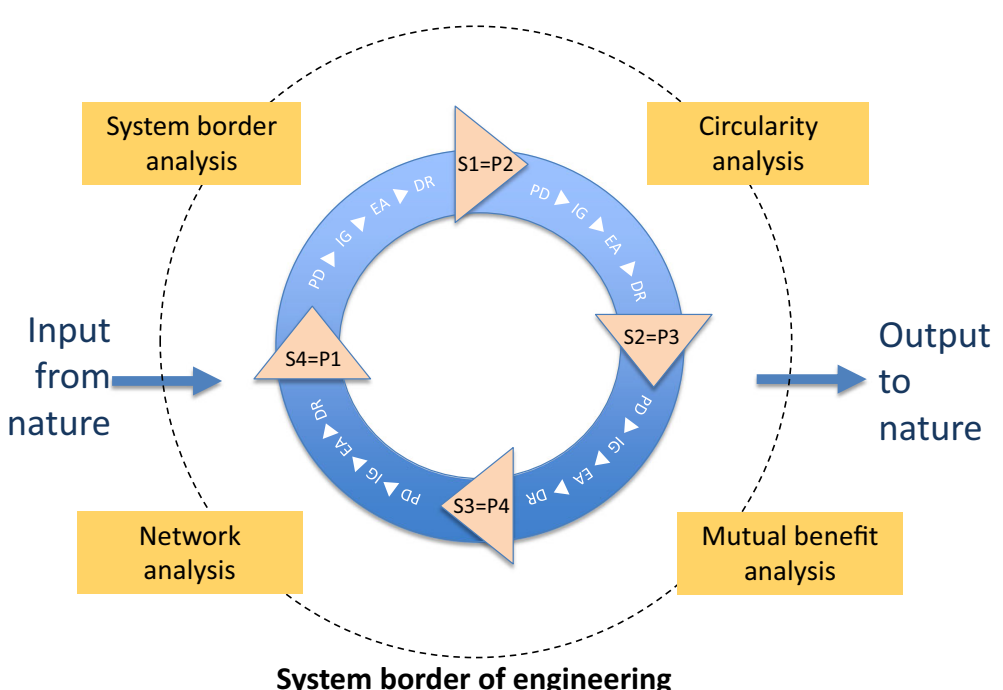

System border of engineering

Fig. 5 Proposed types of analysis in holistic problem-solving

\section{Holistic Problem-Solving}

Problem-solving with the linear engineering design approach (Fig. 1) tends to focus on one or few processes that are designed for a specific purpose. For problems of increasing complexity, several of such processes may be connected in serial mode (Fig. 2). In this type of design, one typically finds wastes, sludges, exhaust fumes, or toxicants that are not regarded as part of the design task and are typically disposed or handled outside the system border of engineering. The history of wastewater treatment as an end-of-pipe approach illustrates this phenomenon (Fig. 2).

In holistic problem-solving, there should be no disposal of waste materials, liquids, or gases outside of the system borders. Thus, designing and engineering this type of (circular) solutions requires either avoidance of certain practices (e.g., waste disposal, wastewater discharge, release of exhaust fumes...) or the design of consecutive solutions for processing possible outputs to keep them in the cycle. Since closing cycles will lead to a vast diversity of new recycling products (e.g., recycled water, fertilizer from urine, soil conditioner from faecal matter, and commodities from recycled carbon), their safety is crucial for their acceptance.

When integrating these issues into a design, the connectedness of seemingly different issues becomes evident. For example, the quality of the recycled water will be influenced by the materials and surfaces it previously was in contact with, as well as by the wastes it carried away. Everything that is brought into a cycle will potentially stay or even accumulate in it, unless it can be completely degraded.

But how can we approach such a complex task with the rigor expected from engineers? We are proposing four conceptual types of analyses that should be developed for holistic problemsolving in engineering design (see Fig. 5). For most of them, the required elements are already existing. Yet, developing them to a set of tools that can be used for holistic problem-solving is an open task for the future. 


\section{Analysis of the System Borders on Different Scales (Spatially, Physically, and Over Time)}

The example of "classical" wastewater treatment (the "Introduction: A Quest for a New Kind of Engineering" section, Fig. 2) illustrates that to save water and achieve a significant recycling of all nutrients, the alluvial sewer system is not an adequate solution. The system border should therefore be drawn at the very beginning of the waste stream: in the toilet. The system border analysis should clarify, what belongs to the system that is to be designed and what does not. The procedure should be stepwise, starting from the core process that needs to be designed and continuing to include all elements and processes relevant in the context of the seven ecological engineering principles (see the "Principles of Ecological Engineering" section).

\section{Network and Interaction Analysis and Keystone Elements}

From ecology we know that a keystone species can have "a disproportionately large effect on its environment relative to its abundance" [64] in an ecosystem. The network and interaction analysis should reveal the degree of cross-linking between the designed system, nature, and other connected elements (e.g., the existing neighborhood) and identify such key-stone elements, users, or organisms. The analysis should visualize the network of factors, players, and their interaction. This could be done, e.g., by cluster analysis or by an extended network analysis [65] that is specifically designed for this purpose.

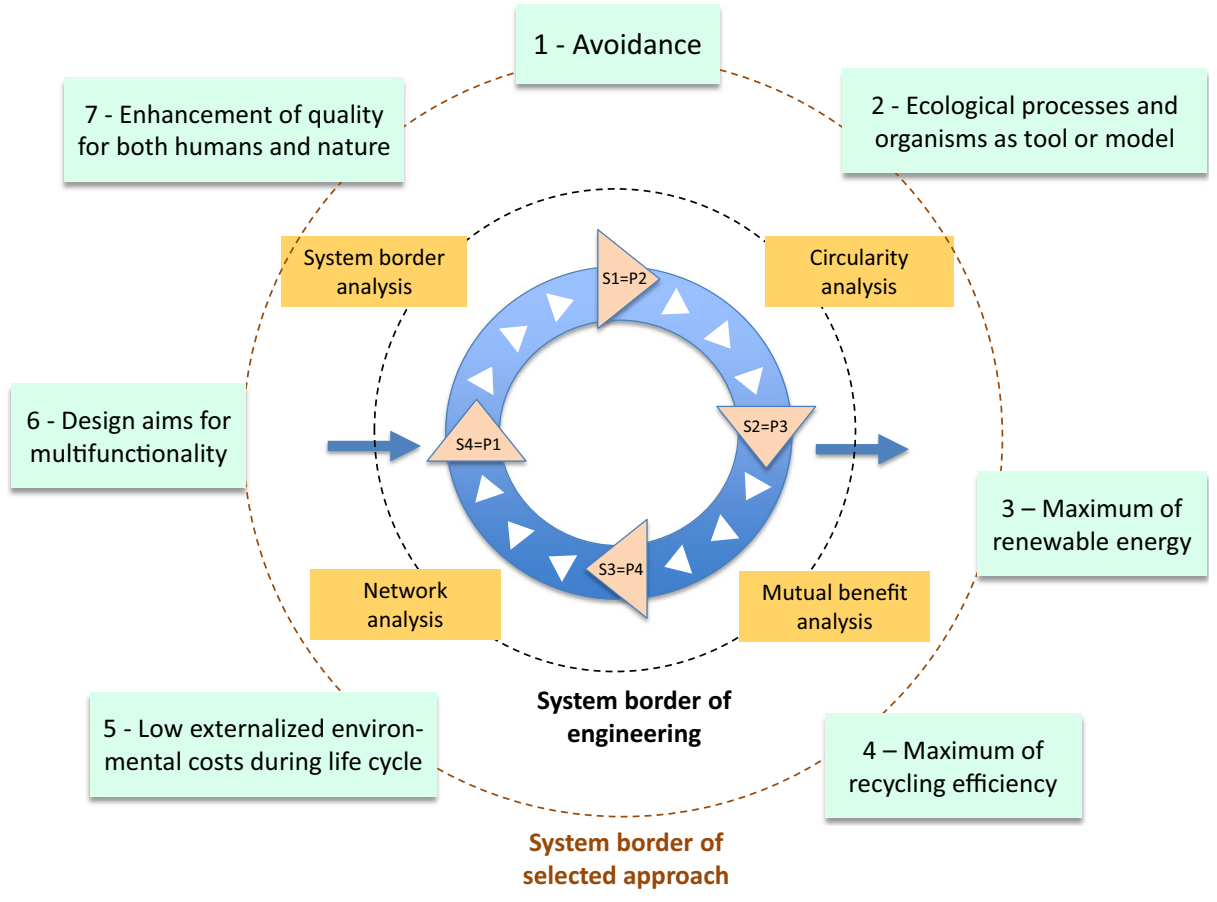

Fig. 6 Guiding Ecological Engineering principles for the assessment of the circular problem-solving process 


\section{Circularity Analysis}

Circularity expresses the function and quality of a system in terms of circular processes. To our knowledge, a general theory of circularity does not exist yet in the context of engineering and needs to be developed. In the context of circular economy, circularity metrics for products and services are under development and may be available in due time [66]. The circularity analysis should focus on material cycles in the context of the designed item, including, e.g., their retention times and turnover rates, interactions, and control as well as the existence of positive or negative feedback loops. Inputs and outputs and the quality of the cycled materials should be part of this analysis.

\section{Mutual Benefit Analysis}

Mutual benefit analysis should allow investigating type, quantity, and quality of interactions between humans and ecosystems as well as their functions and services and evaluate the results in a "valuation framework reaching beyond the scope of ecology and engineering" [67]. It should result in an assessment of the benefits of engineering design projects for humans and ecosystems and support decision-making. Like circularity analysis, the mutual benefit analysis framework still needs to be developed. However, a large body of knowledge on how to support decision-making in complex situations exists in the context of "integrated assessment and its inherent platform, integrated modelling," whose "raison d'être lies in helping to tackle the complex multi-issue problems faced by coupled human-environment systems" [68]. Garver, coming from the side of law and governance, presented a "tool for developing novel law and governance systems that support a mutually enhancing human-Earth relationship" [58]. Alliances with these circles should be sought.

\section{Principles of Ecological Engineering}

In this chapter, a set of seven principles for Ecological Engineering, as we are redefining it, is proposed (Fig. 6). Its purpose is to support future ecological engineers in the circular problemsolving process. We envision the development of a protocol for Good Ecological Engineering Practice that should be embedded into the ongoing process towards a circular economy. To date, such a protocol does not yet exist.

Based on the considerations above, in our view, a good set of ecological engineering principles should:

(i) Be firmly rooted in ecological science and inspired by it

(ii) Have a sufficiently high level of abstraction to be applicable as template for a wide range of cases

(iii) Be measurable

(iv) Involve all stakeholders, including an "advocate of nature"

\section{Principle 1: Avoidance}

Avoidance is the central principle in any ecological engineering project and ought to be considered first. If a perceived need, e.g., for energy supply or wastewater treatment, can be 
avoided or at least drastically reduced, this will reduce its footprint and facilitate the use of ecological processes (principle 2), facilitate supplying the system with $100 \%$ renewable energy (principle 3) and increasing recycling efficiency (principle 4). A design that reduces or avoids potentially harmful constituents and outputs will also improve recycling efficiency of the entire system at the end of its lifetime which has an influence on externalized costs of the system (principle 5). Although this principle is not genuinely derived from ecology, it paves the ground for fulfilling most of the other 6 criteria.

The effects of avoidance can only be measured in comparison to other approaches without an avoidance element. For practical reasons, this comparison will have to be approximated on a conceptual level, because no engineering company will develop two full-fledged projects in parallel just for comparison. A criterion for measuring the effect of avoidance can be the result of the circularity analysis (see the "Principles of Ecological Engineering" section) or the amount of material that leaves the system, compared to the amount that is recycled in it. The unit of the latter would be a mass unit over time.

\section{Principle 2: Ecological Processes and Organisms as Tool or Model for Design}

An ecological engineering project should make use of or emulate functional or structural elements (e.g., processes, structures, and designs) that are described in ecological science. Examples for possible elements are a planted soil element for water treatment, a water retention element that uses a vegetated roof, a cooling element that uses evapotranspiration of plants or structures modelled after termite mounds, a building structure that is stable and durable yet $100 \%$ recyclable, etc. Two of these four examples might work entirely without living organisms (except for microorganisms). Others can be termed Nature Based Units or -Solutions [69].

A criterion for assessing the implementation of this principle could be the number of respective elements in a design, compared to a design without these elements. The development of a positive list of such elements is necessary before this principle can be assessed. Another criterion could be the performance over time.

\section{Principle 3: Maximum of Renewable Energy (During Operation)}

An ecological engineering project should aim to reach a $100 \%$ energy supply from renewable resources over its lifetime. The Earth's ecosystems are powered to a very large degree by solar energy, with the only exception of a few spots in volcanic areas or at the bottom of the ocean, where some ecosystems are powered by geothermal energy. All renewable energies on Earth (e.g., wind-, hydro-, or wave power, biomass to fuel) are derived directly or indirectly from solar energy.

An indicator for assessing this principle is the percentage of renewable energy in relation to the total energy demand of the system, measured in energy units over time.

\section{Principle 4: Maximum of Recycling Efficiency (During Operation)}

An ecological engineering project should aim to reach a high recycling efficiency within its system borders. In Earth's biosphere, organic wastes such as excreta or dead organisms are often degraded completely where they accrue, through the action of decomposers (saprovores, detritus feeders, microorganisms). A model for this is an undisturbed rainforest which rapidly recycles nutrients and organic materials to almost the full extent [60]. 
The formation of material deposits is another aspect and requires separate consideration. In Earth's biosphere, a large diversity of material deposits can be found. Some of them are deposited for geologically short times, until they reenter the biosphere (e.g., snow or ice in glaciers). Others, such as precipitates in sediments of lakes, rivers, or oceans, are converted into sedimentary rocks over time and remain stable for geological time spans.

From an ecological engineering perspective, material deposits can also be part of a system design, if direct recycling is currently not possible, if they are needed to stabilize a system (e.g., a life-support system in space), if the deposits are stable, and if a later reuse is still possible.

The indicator for assessing recycling process efficiency is the amount of material leaving the system in relation to the amount of material recycled within the system, measured in mass units over time. Reusable material deposits are regarded as system elements, while long-term deposits should be regarded as elements outside the system borders.

\section{Principle 5: Low Externalized Environmental Costs During the Entire Life Cycle}

In ecological engineering project should aim to minimize externalized costs throughout its life cycle. The environmental footprint of the materials used in a system (water consumption, $\mathrm{CO}_{2}$ production, energy consumption for recycling, etc.) should be minimized. The aim is to design structures that can be completely recycled and reused, while the process is powered by renewable energy.

This principle can be assessed using methods for life-cycle analysis. The results can be expressed, e.g., in environmental impact points.

\section{Principle 6: Design Aims for Multifunctionality}

An ecological engineering design should always seek to harness multiple functions. System size and the delineation of system borders are very important for this principle. A constructed wetland, for example, may be a wastewater treatment element (function 1); a biotope for insects, amphibians, or birds (function 2); and a recreation area (function 3). If it is part of a zero-effluent concept and only needs to treat the excess greywater or rooftop runoff, it might be designed as fishing pond or water garden (function 4). If its size is large enough, it may also have a cooling function (function 5) for a building or a neighborhood.

This principle can be assessed by counting and evaluating the functions the design aims to fulfill. Like principle 2, this principle will require discussions and the development of a positive list in the future, which defines what is considered a function. In addition, it will require rules for system delineation.

\section{Principle 7: Enhancement of Quality for Both Humans and Nature}

An ecological engineering design should aim to improve the quality of life of the beneficiaries. These can be the inhabitants (i.e., of a building), a neighborhood (i.e., of a pond, a green wall, or wetland), different age- or ethnical groups (i.e., a park), and flora and fauna habitats for different species (i.e., all sorts of green building elements). The key issue of this principle is to 
invite participation of stakeholders as part of the design process. This is also closely related to the principles for creating resilience in Biggs et al. [35]: foster participation and foster learning.

The enhancement of quality can be assessed, e.g., by conducting surveys or running focus groups as part of an integrated assessment on the benefit of a project. It can be reached, e.g., by actively engaging stakeholders (one of them being an "advocate for nature") in the project development. Perception of quality is a highly subjective matter. We are aware that this criterion cannot be directly derived from ecology, and it is the most demanding and sensitive criterion of all.

\section{Conclusion}

Ecological Engineering, as we propose to redefine it, integrates ecological principles, processes, and organisms with existing engineering practice to a holistic approach for problemsolving. With this redefinition, we want to advance the transformation of engineering thinking into a more holistic way of thinking. We propose seven principles with quantifiable criteria that allow an assessment, how well this definition is reached in a project, pointing the way towards a future label that can be conferred to Good Ecological Engineering Practice

The widespread use of the linear problem-solving process in engineering design led to an amazing advancement of technology during the last centuries. It has been a key factor for increased wealth and wellbeing for many people. The next big challenge will be to develop a more sustainable human society that respects the planetary boundaries [8]. In our perspective, current mainstream engineering thinking is increasingly becoming a part of the problem in this process.

Human society has been developing means to significantly influence and change all global processes. From the top of the highest mountains, to glaciers and polar icecaps, to the deepest point in the oceans, no place on Earth remains unaffected by human activities. A continued focus on solving problems in a linear way does not account for the increasingly complex situation we find ourselves in.

The proposed change of paradigm towards a more integrated type of engineering, that is in line with current theories about planetary boundaries [8], resilience [35], circular economy $([66,70])$, and the role of nature based solutions for circular economy [68] has the potential to lead to a wealth of interesting new integrated approaches, technologies, and solutions. This will be essential for achieving a more sustainable society in balance with its natural environment, "for the benefit of both." The classical skills of engineers are needed in this new type of engineering but need to be integrated with solid understanding of ecological processes and the skills to solve future problems in a holistic way. We think that "ecological engineering" is a suitable name for the new paradigm of engineering described in this study.

Acknowledgements A cordial thank you to David Austin, Puneet Srivastava, Glenn Dale, Bernhard Wehrli, Marc Kößler, Florin Schönborn, Remo Wiegand, Hannah Kröhnert, Mira Bleuler, Devi Bühler, Dominik Refardt, and Francis Froborg, who all helped developing this text by giving valuable feedback at different stages since version 0.1 of summer 2017. Thank you also to the students of the Master's Program "Environment and Natural Resources" of the Institute of Natural Resources Science at ZHAW, who attended the "Ecological Engineering" module in 2017, 2018, or 2019, for being such an attentive, critical, yet constructive test audience. The key concepts of this paper were first presented to the public at the IEES/ZHAW online Symposium "Closed Cycles and the Circular Society" in Waedenswil, Switzerland, Sep. 2, 2020.

Code Availability No code.

Author's Contribution Andreas Schönborn and Ranka Junge are both full authors. 
Funding Open Access funding provided by ZHAW Zürcher Hochschule für Angewandte Wissenschaften. The work was originally developed as course material for the module "Ecological Engineering" of the MSc program "Environment and Natural Resources" at ZHAW Wädenswil, Switzerland.

Data Availability No data or material.

\section{Declarations}

Conflict of Interest The authors declare no competing interests.

Open Access This article is licensed under a Creative Commons Attribution 4.0 International License, which permits use, sharing, adaptation, distribution and reproduction in any medium or format, as long as you give appropriate credit to the original author(s) and the source, provide a link to the Creative Commons licence, and indicate if changes were made. The images or other third party material in this article are included in the article's Creative Commons licence, unless indicated otherwise in a credit line to the material. If material is not included in the article's Creative Commons licence and your intended use is not permitted by statutory regulation or exceeds the permitted use, you will need to obtain permission directly from the copyright holder. To view a copy of this licence, visit http://creativecommons.org/licenses/by/4.0/.

\section{References}

1. United Nations (2015) Sustainable development goals. Sustainable Development Goals https://www.un.org/ sustainabledevelopment/ (

2. UNFCCC (2018) The Paris Agreement. United Nations Climate Change https://unfccc.int/process-andmeetings/the-paris-agreement/the-paris-agreement (

3. Flohr P, Fleitmann D, Zorita E, Sadekov A, Cheng H, Bosomworth M, Edwards L, Matthews W, Matthews $\mathrm{R}$ (Feb. 2017) Late Holocene droughts in the Fertile Crescent recorded in a speleothem from northern Iraq. Geophys Res Lett 44(3):1528-1536. https://doi.org/10.1002/2016GL071786

4. Butler R (2018) Amazone destruction. Mongabay https://rainforests.mongabay.com/amazon/amazon destruction.html (

5. D. L. A. Gaveau et al., "Four decades of forest persistence, clearance and logging on Borneo," PLoS ONE, vol. 9, no. 7, 2014, https://doi.org/10.1371/journal.pone.0101654.

6. Golden $\mathrm{C}$ et al (2016) Fall in fish catch threatens human health. Nature 534(7607):317-320

7. Jambeck JR et al (2015) Plastic waste inputs from land into the ocean. Science 347:6223-6768. https://doi. org/10.1126/science. 1260352

8. Steffen W, Richardson K, Rockstrom J, Cornell SE, Fetzer I, Bennett EM, Biggs R, Carpenter SR, de Vries W, de Wit CA, Folke C, Gerten D, Heinke J, Mace GM, Persson LM, Ramanathan V, Reyers B, Sorlin S (Feb. 2015) Planetary boundaries: guiding human development on a changing planet. Science 347(6223): 1259855-1259855. https://doi.org/10.1126/science.1259855

9. Dodds R, Venables R (eds) (2005) Engineering for sustainable development: guiding principles. Royal Academy of Engineering, London, England

10. World Commission on Environment and Development, Our common future. Oxford; New York: Oxford University Press, 1987.

11. J. Clarkson and C. Eckert, Eds., Design process improvement: a review of current practice, 2005th ed. London U.K.: Springer, 2004.

12. Sobek DK, Jain VK (2007) Process factors affecting design quality: a virtual design of experiments approach. J Mech Des 129(5):483-490

13. Lofrano G, Brown J (Oct. 2010) Wastewater management through the ages: a history of mankind. Sci Total Environ 408:5254-5264. https://doi.org/10.1016/j.scitotenv.2010.07.062

14. Lange J, Otterpohl R, Steger-Hartmann T (1997) Abwasser: Handbuch zu einer zukunftsfähigen Wasserwirtschaft. Mall-Beton-Verl, Donaueschingen-Pfohren

15. Kosek K, Luczkiewicz A, Fudala-Książek S, Jankowska K, Szopińska M, Svahn O, Tränckner J, Kaiser A, Langas V, Björklund E (Oct. 2020) Implementation of advanced micropollutants removal technologies in wastewater treatment plants (WWTPs) - Examples and challenges based on selected EU countries. Environ Sci Pol 112:213-226. https://doi.org/10.1016/j.envsci.2020.06.011

16. Donatello S, Cheeseman CR (Nov. 2013) Recycling and recovery routes for incinerated sewage sludge ash (ISSA): a review. Waste Manag 33(11):2328-2340. https://doi.org/10.1016/j.wasman.2013.05.024 
17. Chertow MR (2008) 'Uncovering' Industrial Symbiosis. J Ind Ecol 11(1):11-30. https://doi.org/10.1162/ jiec.2007.1110

18. Chertow MR (Nov. 2000) INDUSTRIAL SYMBIOSIS: literature and taxonomy. Annu Rev Energy Environ 25(1):313-337. https://doi.org/10.1146/annurev.energy.25.1.313

19. Galloway JN, Leach AM, Bleeker A, Erisman JW (2013) A chronology of human understanding of the nitrogen cycle. Philos Trans R Soc B Biol Sci 368:1621-20130120. https://doi.org/10.1098/rstb.2013.0120

20. Galvez ME, Gaillardet J (2012) Historical constraints on the origins of the carbon cycle concept. Compt Rendus Geosci 344(11-12):549-567. https://doi.org/10.1016/j.crte.2012.10.006

21. W. J. Mitsch, "Ecological engineering: the roots and rationale of a new ecological paradigm," presented at the Ecological Engineering for Wastewater Treatment, Sweden, 1991.

22. Busch K-F, Uhlmann D, Weise G (1989) Ingenieurökologie, 2. Auflage edn. Jena, VEB Gustav Fischer Verlag

23. W. Mitsch and S. E. Jørgensen, Ecological engineering: an introduction to ecotechnology. 1989.

24. Kangas PC (2004) Ecological engineering: principles and practice. Lewis Publishers, Boca Raton

25. Van Bohemen HD (2004) Ecological engineering and civil engineering works. TU Delft, Netherlands

26. J. Staudenmann, A. Schönborn, and C. Etnier, "Recycling the resource - ecological engineering for wastewater treatment," 1996, vol. 5-6, p. 479 pp.

27. B. Guterstam and C. Etnier, Eds., "Ecological engineering for wastewater treatment. Proceedings of the Conference at Stensund Folk College," in Ecological engineering for wastewater treatment. Proceedings of the International Conference held at Stensund Folk College, Sweden, March 24-28, 1991., Stensund Folk College, Sweden, Mar. 1991, vol. 2nd Edition, pp. 38-54.

28. L. Thofelt and A. Englund, Eds., "Ecotechnics for a sustainable society. Proceedings from Ecotechnics 95: International Symposium on Ecological Engineering," Frösön, Sweden, 1996.

29. B. Kløve, C. Etnier, P. Jenssen, and T. Maehlum, Eds., "Managing the wastewater resource - ecological engineering for wastewater treatment," Ås, Norway, 1999.

30. Staudenmann J, Junge-Berberović R (2003) The Otelfingen aquaculture project : recycling of nutrients from waste water in a temperate climate. J Appl Aquac 13(1-2):67-101. https://doi.org/10.1300/J028v13n01_04

31. B. B. Jana, R. D. Banerjee, B. Guterstam, and J. Heeb, Eds., "Waste recycling and resource management in the developing world - ecological engineering approach," University of Kalyani, Kalyani / Wolhusen, Switzerland, 2000.

32. Gattie DK, Smith MC, Tollner EW, McCutcheon SC (Oct. 2003) The emergence of ecological engineering as a discipline. Ecol Eng 20(5):409-420. https://doi.org/10.1016/j.ecoleng.2003.08.003

33. Dictonary C Holistic. Cambridge Dictonary https://dictionary.cambridge.org/dictionary/english/holistic (

34. Merriam-Webster, "Anthropocentrism," Merriam-Webster. https://www.merriam-webster.com/dictionary/ anthropocentrism (accessed Aug. 12, 2018).

35. R. Biggs, M. Schlüter, and M. Schoon, Principles for building resilience. sustaining ecological services in social-ecological systems. Cambridge University Press.

36. "Nature," Wikipedia. Aug. 28, 2019, Accessed: Aug. 12, 2018. [Online]. Available: https://en.wikipedia. org $/$ w/index.php?title $=$ Nature\&oldid $=912923881$.

37. Merriam-Webster (2018) Environment. Merriam-Webster https://www.merriam-webster.com/dictionary/ environment (

38. Merriam-Webster (2018) Engineering. Merriam-Webster https://www.merriam-webster.com/dictionary/ engineering (

39. Jessop R (2012) Coinage of the term environment: a word without authority and Carlyle's displacement of the mechanical metaphor. Lit Compass 9(11):708-720. https://doi.org/10.1111/j.1741-4113.2012.00922.x

40. "Web of Science." Accessed: Jan. 24, 2021. [Online]. Available: https://apps.webofknowledge.com/.

41. “Google Scholar.” Accessed: Jan. 24, 2021. [Online]. Available: https://scholar.google.ch/.

42. Straškraba M (Dec. 1993) Ecotechnology as a new means for environmental management. Ecol Eng 2(4): 311-331. https://doi.org/10.1016/0925-8574(93)90001-V

43. Bergen SD, Bolton SM, Fridley JL (Dec. 2001) Design principles for ecological engineering. Ecol Eng 18(2):201-210. https://doi.org/10.1016/S0925-8574(01)00078-7

44. Odum HT, Odum B (Oct. 2003) Concepts and methods of ecological engineering. Ecol Eng 20(5):339-361. https://doi.org/10.1016/j.ecoleng.2003.08.008

45. Mitsch WJ, Jørgensen SE (2003) Ecological engineering: a field whose time has come. Ecol Eng 20(5): 363-377. https://doi.org/10.1016/j.ecoleng.2003.05.001

46. Gosselin F (Mar. 2008) Redefining ecological engineering to promote its integration with sustainable development and tighten its links with the whole of ecology. Ecol Eng 32(3):199-205. https://doi.org/10. 1016/j.ecoleng.2007.11.007

47. "Ecological engineering - the journal of ecosystem restoration,." Accessed: Jan. 05, 2021. [Online]. Available: https://www.journals.elsevier.com/ecological-engineering/. 
48. Barot S, Lata J-C, Lacroix G (Aug. 2012) Meeting the relational challenge of ecological engineering within ecological sciences. Ecol Eng 45:13-23. https://doi.org/10.1016/j.ecoleng.2011.04.006

49. K. Pietro, R. Bearzotti, M. Chimney, G. Germain, N. Iricanin, and T. Piccone, "Chapter 5: STA performance, compliance and optimization," South Florida Environmental Report, South Florida Water Management District, 2007. Accessed: Sep. 05, 2018. [Online]. Available: http://my.sfwmd.gov/portal/ page/portal/pg_grp_sfwmd_sfer/portlet_prevreport/volume1/vol1_table_of_contents.html.

50. Mitsch WJ, Yan J, Cronk JK (Sep. 1993) Ecological engineering - contrasting experiences in China with the West. Ecol Eng 2(3):177-191. https://doi.org/10.1016/0925-8574(93)90013-6

51. Todd J, Josephson B (May 1996) The design of living technologies for waste treatment. Ecol Eng 6(1):109136. https://doi.org/10.1016/0925-8574(95)00054-2

52. Guterstam B (May 1996) Demonstrating ecological engineering for wastewater treatment in a Nordic climate using aquaculture principles in a greenhouse mesocosm. Ecol Eng 6(1):73-97. https://doi.org/10. 1016/0925-8574(95)00052-6

53. Zheng J, Wei X, Liu Y, Liu G, Wang W, Liu W (Aug. 2016) Review of regional carbon counting methods for the Chinese major ecological engineering programs. J For Res 27(4):727-738. https://doi.org/10.1007/ s11676-016-0256-8

54. X. Liu et al., "Ecological engineering in pond aquaculture: a review from the whole-process perspective in China," Rev. Aquac., p. raq.12512, Nov. 2020, 10.1111/raq.12512.

55. "3rd International Conference on Advances in Civil and Ecological Engineering Research (ACEER 2021)." Accessed: Jan. 05, 2021. [Online]. Available: http://www.aceerconf.org/.

56. M. Wu et al., "Review of ecological engineering solutions for rural non-point source water pollution control in Hubei Province, China," Water. Air. Soil Pollut., vol. 224, no. 5, p. 1561, May 2013, 10.1007/s11270-013-1561-x.

57. Costanza R, d'Arge R, de Groot R, Farber S, Grasso M, Hannon B, Limburg K, Naeem S, O'Neill RV, Paruelo J, Raskin RG, Sutton P, van den Belt M (1998) The value of the world's ecosystem services and natural capital. Ecol Econ 25(1):3-15

58. Garver G (Mar. 2019) A systems-based tool for transitioning to law for a mutually enhancing human-earth relationship. Ecol Econ 157:165-174. https://doi.org/10.1016/j.ecolecon.2018.09.022

59. Begon M, Howarth RW, Townsend CR (2017) Ökologie, 3. Auflage edn. Berlin, Heidelberg, Springer Berlin Heidelberg

60. Forti MC, Neal C (1992) Hydrochemical cycles in tropical rainforests: an overview with emphasis on Central Amazonia. J Hydrol 134(1-4):103-115. https://doi.org/10.1016/0022-1694(92)90031-P

61. Likens GE, Bormann FH, Johnson NM, Fisher DW, Pierce RS (1970) Effects of forest cutting and herbicide treatment on nutrient budgets in the Hubbard Brook watershed-ecosystem. Ecol Monogr 40(1):23-47

62. Ellis EC (Aug. 2015) Ecology in an anthropogenic biosphere. Ecol Monogr 85(3):287-331. https://doi.org/ $10.1890 / 14-2274.1$

63. International Ecological Engineering Society (2018) Ecological engineering. IEES https://iees.ch/ ecological-engineering-2/ (

64. Paine RT (1995) A conversation on refining the concept of keystone species. Conserv Biol 9(4):962-964. https://doi.org/10.1046/j.1523-1739.1995.09040962.x

65. A. M. Chiesi, "Network analysis," in International Encyclopedia of the Social \& Behavioral Sciences, Elsevier, 2015, pp. 518-523.

66. Corona B, Shen L, Reike D, Rosales Carreón J, Worrell E (Dec. 2019) Towards sustainable development through the circular economy - a review and critical assessment on current circularity metrics. Resour Conserv Recycl 151:104498. https://doi.org/10.1016/j.resconrec.2019.104498

67. Brüll A, van Bohemen H, Costanza R, Mitsch WJ, van den Boomen R, Chaudhuri N, Heeb J, Jenssen P, Kalin M, Schönborn A (2011) Benefits of ecological engineering practices. Procedia Environ Sci 9:16-20

68. Hamilton SH, ElSawah S, Guillaume JHA, Jakeman AJ, Pierce SA (Feb. 2015) Integrated assessment and modelling: overview and synthesis of salient dimensions. Environ Model Softw 64:215-229. https://doi.org/ 10.1016/j.envsoft.2014.12.005

69. Langergraber G, Pucher B, Simperler L, Kisser J, Katsou E, Buehler D, Mateo MCG, Atanasova N (Jan. 2020) Implementing nature-based solutions for creating a resourceful circular city. Blue-Green Syst 2(1):173-185. https://doi.org/10.2166/bgs.2020.933

70. Reike D, Vermeulen WJV, Witjes S (Aug. 2018) The circular economy: new or refurbished as CE 3.0? exploring controversies in the conceptualization of the circular economy through a focus on history and resource value retention options. Resour Conserv Recycl 135:246-264. https://doi.org/10.1016/j.resconrec. 2017.08.027 